\title{
Prediksi Kepuasan Layanan Akademik Menggunakan Algoritma Nä̈ve Bayes
}

\author{
${ }^{1}$ Khurotul Aeni, M.Kom, ${ }^{2}$ M. Faisal Asy'ari, S.Kom \\ ${ }^{1,2}$ Universitas Peradaban, Paguyangan-Brebes \\ ${ }^{3}$ Jurusan Teknik Informatika, Fakultas Sains \& Teknologi \\ e-mail: *11khaeni988@gmail.com, ${ }^{2}$ faisal.faadi@gmail.com
}

\begin{abstract}
Abstrak
Berdasarkan Badan Akreditasi Nasional Perguruan Tinggi (BAN-PT), tuntutan yang diberikan masyarakat kepada perguruan tinggi meliputi jaminan kualitas (quality assurance), pengendalian kualitas (quality control), dan perbaikan kualitas (quality improvement) [1]. Untuk meningkatkan kualitas dalam pelayanan akademik diperguruan tinggi bisa melakukan evaluasi atau prediksi kinerja layanan berbasis IT tersebut, hal ini dilakukan untuk mengetahui sejauh mana nilai dan kualitas dari pelayanan yang diberikan oleh pihak perguruan tinggi kepada penggunanya. Data mining merupakan salah satu ilmu yang dapat digunakan untuk melakukan peramalan yang akurat dalam mengetahui kelayakan dimasa yang akan datang serta mampu melakukan optimasi dalam proses mencari informasi dalam basis data yang besar dan mampu menemukan pola-pola yang tidak diketahui sebelumnya. Dengan menggunakan data mining maka pencarian data dari system prediksi kepuasan pelayanan akademik dapat dilakukan [2]. Sedangkan Nä̈ve Bayes merupakan teknik mengklasifikasikan probabilitas sederhana yang mengaplikasikan teorema bayes yang mampu mengolah data kuantitatif dan data diskrit untuk perhitungan estimasi peluang yang dibutuhkan untuk klasifikasi [3]. Atribut yang digunakan NIM, Jenis Kelamin, Kelas Mahasiswa, Layanan informasi perkuliahan, layanan keamanan data pribadi serta layanan informasi nilai, dengan menggunakan algoritma nä̈ve bayes berhasil memprediksi layanan akademik sebesar 52\% dengan data training sebesar 100 data dan data uji 17 data.
\end{abstract}

Kata kunci-3-5 Data Mining, Nä̈ve Bayes, Prediksi, Layanan Akademik

\begin{abstract}
Based on the National Accreditation Board of Higher Education (BAN-PT), the demands that the community give to universities include quality assurance, quality control, and quality improvement. To improve the quality in academic services in higher education can evaluate or predict the performance of it-based services, this is done to know the extent of the value and quality of the services provided by the college to its users. Data mining is one of the sciences that can be used to perform accurate forecasting in knowing future feasibility and being able to optimize the process of finding information in a large database and being able to find previously unknown patterns. By using data mining, the search for data from the academic service satisfaction prediction system can be done. While Nä̈ve Bayes is a simple probability classifying technique that applies bayes theorem that is able to process quantitative data and discrete data for the calculation of estimated opportunities needed for classification. Attributes used by NIM, Gender, Student Class, Lecture information services, personal data security services and value information services, using naïve bayes algorithm managed to predict academic services by 52\% with training data of 100 data and test data 17 data.
\end{abstract}

Keywords - Data Mining, Nä̈ve Bayes, Prediction, Academic Services 


\section{PENDAHULUAN}

Pendidikan tidak bisa lepas dari kehidupan manusia, adanya kemampuan dan pengetahuan merupakan modal yang dimiliki manusia untuk hidup di era digital saat ini, kesadaran masyarakat terhadap nilai pendidikan perguruan tinggi menimbulkan tuntutan dari masyarakat terhadap kualitas perguruan tinggi. Berdasarkan Badan Akreditasi Nasional Perguruan Tinggi (BAN-PT), tuntutan yang diberikan masyarakat kepada perguruan tinggi meliputi jaminan kualitas (quality assurance), pengendalian kualitas (quality control), dan perbaikan kualitas (quality improvement) [1]. Hal yang dapat dilakukan untuk meningkatkan kualitas perguruan tinggi salah satunya adalah memberikan kemudahan dan kepuasan kepada penggunanya, sebagai contoh penggunaan layanan akademik berbasis IT pada perguruan tinggi. Untuk meningkatkan kualitas dalam pelayanan akademik diperguruan tinggi bisa melakukan evaluasi atau prediksi kinerja layanan berbasis IT tersebut, hal ini dilakukan untuk mengetahui sejauh mana nilai dan kualitas dari pelayanan yang diberikan oleh pihak perguruan tinggi kepada penggunanya.

Data mining merupakan salah satu ilmu yang dapat digunakan untuk melakukan peramalan yang akurat dalam mengetahui kelayakan dimasa yang akan datang. Data mining mampu melakukan optimasi dalam proses mencari informasi dalam basis data yang besar dan mampu menemukan pola-pola yang tidak diketahui sebelumnya. Dengan menggunakan data mining maka pencarian data dari system prediksi kepuasan pelayanan akademik dapat dilakukan [2]. Sedangkan Nä̈ve Bayes merupakan teknik mengklasifikasikan probabilitas sederhana yang mengaplikasikan teorema bayes yang mampu mengolah data kuantitatif dan data diskrit untuk perhitungan estimasi peluang yang dibutuhkan untuk klasifikasi [3].

Penelitian sebelumnya pernah dilakukan oleh Dedy dan Danny [2] dalam mempredeksi kelayakan kredit menggunakan algoritma nä̈ve bayes pada BMT Beringharjo Yogyakarta dengan teknik survey, pada penelitian ini tingkat akurasi yang diperoleh sebesar 92,5\% dengan tingkat error 7,5\% dari 160 data yang digunakan untuk training dan 40 untuk testing, pada penelitian ini juga berhasil menerapkan algoritma nä̈ve bayes untuk memprediksi kelayakan kredit pada BMT Beringharjo Yogyakarta. Penelitian lain dengan menggunakan data mining juga dilakukan oleh Annisak [4], pada penelitian ini Annisak menggunakan algoritma yang berbeda dengan Dedy dan Danny yaitu algoritma C4.5, dengan algoritma C4.5 Annisak menganalisa jumlah pelanggan yang aktif dan tidak aktif sebagai kriteria dalam penilaian dengan mengolah variable PO Pertahun, diskon, jumlah barang dan total pembelian, hasil pengolahan algoritma C4.5 juga dapat membentuk pohon keputusan (decision tree) yang diproses oleh WEKA dalam menganalisis jumlah pelanggan yang aktif.

Dengan adanya pengolahan data berbasis data mining tersebut, maka diharapkan mampu menjawab persoalan yang saat ini terjadi, yaitu bagaimana memprediksi kepuasan pelanggan terhadap layanan akademik dan mampu mengetahui tingkat akurasi kepuasan layanan akademik dengan algoritma Nä̈ve Bayes pada perguruan tinggi.

\section{METODE PENELITIAN}

\section{Data Mining}

Data mining menurut (Alimancon Sijabat, 2015) [4] merupakan proses yang memperkerjakan satu atau lebih teknik pembelajaran komputer untuk menganalisis dan mengekstrak pengetahuan secara otomatis atau serangkaian proses untuk menggali nilai tambah dari suatu kumpulan data berupa pengetahuan yang selama ini tidak diketahui secara manual. Informasi yang dihasilkan dari data mining mampu digunakan pada beberapa 
bidang, seperti perbankan [5], instansi pemerintah [6], asuransi [7], perguruan tinggi [1], [3], [8],[12], dll.

2. Nä̈ve Bayes

Menurut (Kusrini dan Luthfi, 2009) [7] Bayesian classification adalah pengklasifikasian statistik yang dapat digunakan untuk memprediksi probabilitas keanggotaan suatu class. Bayesian classification didasarkan pada teorema Bayes yang memiliki kemampuan klasifikasi serupa dengan decesion tree dan neural network. Bayesian classification terbukti memiliki akurasi dan kecepatan yang tinggi saat diaplikasikan ke dalam database dengan data yang besar. Teorema Bayes memiliki bentuk umum sebagai berikut:

$P(Y \mid X)=P X Y P(Y) / P(X)$

Keterangan:

$\mathrm{X}$ : Data dengan kelas yang belum diketahui

$\mathrm{Y}$ : Hipotesis data $\mathrm{X}$ adalah suatu kelas spesifik

$\mathrm{P}(\mathrm{Y} \mid \mathrm{X})$ : Probabilitas hipotesis $\mathrm{Y}$ berdasar kondisi $\mathrm{X}$

$\mathrm{P}(\mathrm{Y}) \quad$ : Probabilitas hipotesis $\mathrm{Y}$

$\mathrm{P}(\mathrm{X} \mid \mathrm{Y})$ : Probabilitas $\mathrm{X}$ berdasarkan kondisi pada saat hipotesis $\mathrm{Y}$

$\mathrm{P}(\mathrm{X}) \quad$ : Probabilitas $\mathrm{X}$

3. Metode

Metode penelitian yang digunakan dapat dilihat pada Gambar 1.

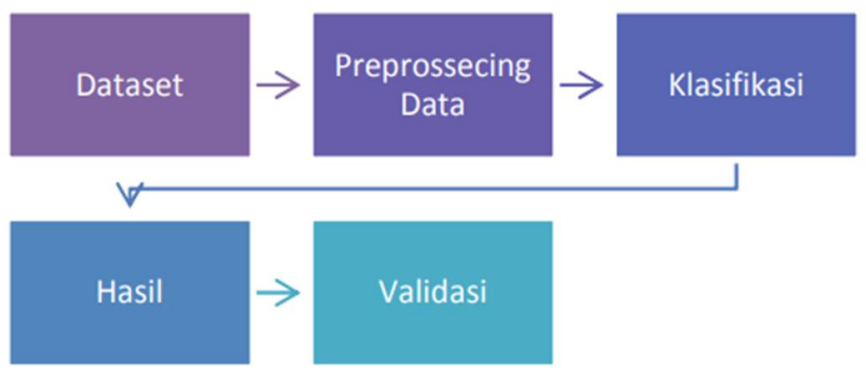

Gambar 1. Metode Penelitian

\section{Keterangan Gambar 2 Metode Penelitian:}

1) Dataset yang dikumpulkan untuk prediksi kepuasan pelayanan akademik diambil dari data kuesioner. Kuesioner yang diambil dari mahasiswa jurusan Teknik Informatika Angkatan 2016-2019, indikator dalam pembuatan kuesioner akan dijadikan dataset, indikator tersebut antara lain:

a) Nim mahasiswa.

b) Jenis kelamain.

c) Kelas mahasiswa.

d) Layanan informasi perkuliahan.

e) Layanan keamanan data pribadi.

f) Layanan informasi nilai.

g) Layanan pengajuan judul skripsi.

Dari dataset di atas akan di bagi menjadi dua bagian yaitu Data latih dan Data uji. Untuk data latih yang diambil sebesar $60 \%$ dan data uji sebesar $40 \%$ dimana akan dilakukan pengklasifikasian menggunakan Nä̈ve Bayes untuk menghasilkan sebuah keputusan "kepuasan" dan "ketidakpuasan" bagi mahasiswa dalam pelayanan akademik di Universitas Peradaban. 
2) Untuk Preprossecing Data yang dilakukan adalah dengan mengubah data kuesioner kedalam ms.excel, selanjutnya dilakukan analisis, identifikasi, serta memperbaiki data yang ganda, data yang tidak konsisten, dan membersihkan data dari noisy.

3) Klasifikasi yang digunakan yaitu Nä̈ve Bayes, untuk proses klasifikasi dengan Nä̈ve Bayes dapat dilihat pada Gambar 2.

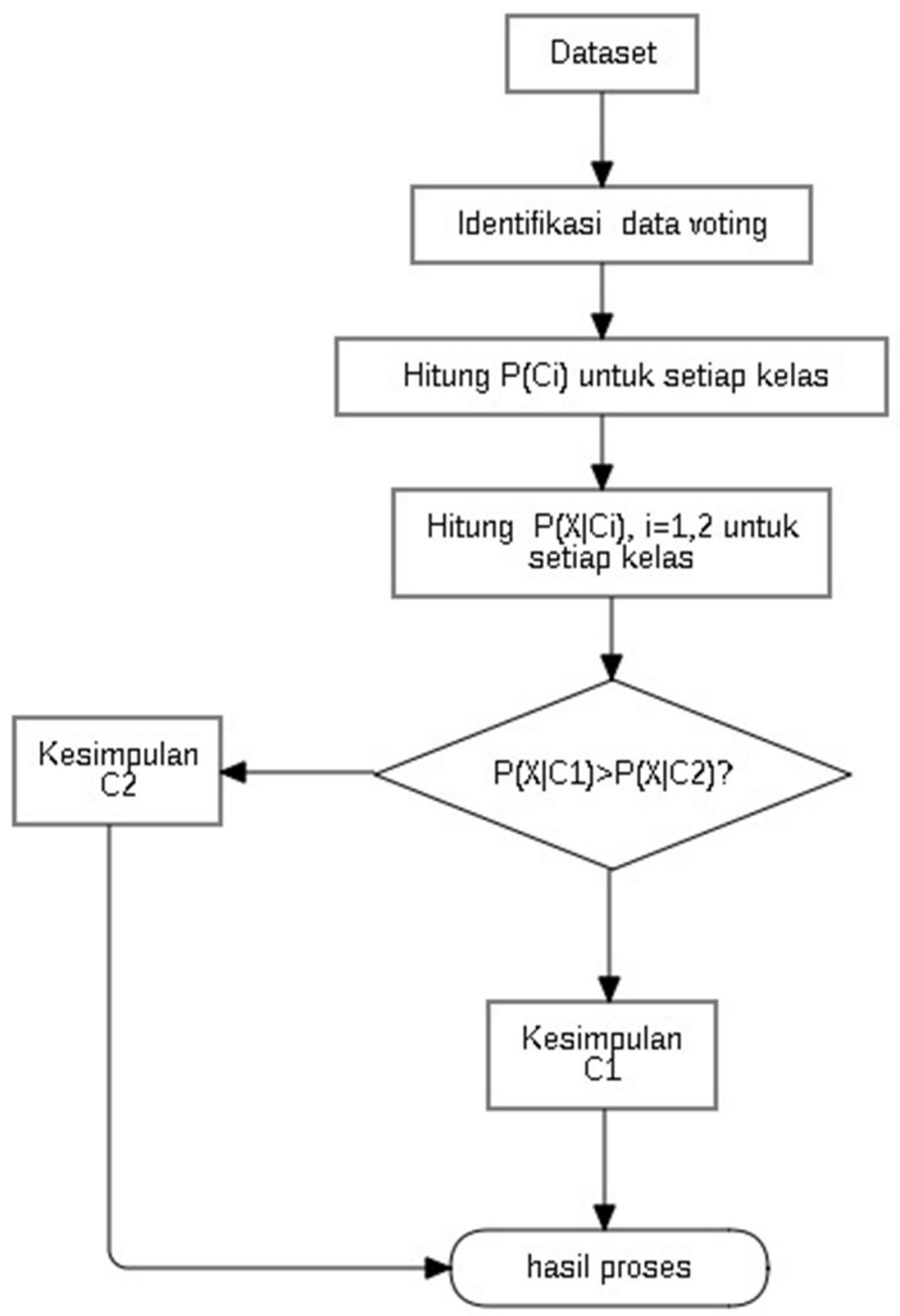

Gambar 2. Pemodelan Naïve Bayes

Dari dataset, kemudian identifikasi dataset voting. Hitung P (Ci) untuk setiap atribut, dalam kasus dataset pada penelitian ini yaitu atribut tahun, jenis kelamin, kategori mahasiswa yang terdiri dari 2 kelas yaitu kelas karyawan dan kelas regular, serta jawaban puas dan tidak puas. Kemudian hitung $\mathrm{P}(\mathrm{X} \mid \mathrm{Ci}), \mathrm{i}=1,2$ untuk setiap kelas atau atribut. Setelah itu dibandingkan, jika $\mathrm{P}(\mathrm{X} \mid \mathrm{C} 1)>(\mathrm{P}\{\mathrm{X} \mid \mathrm{C} 2)$ maka kesimpulannya $\mathrm{C} 1$ adalah Puas = "Puas" dan jika $\mathrm{P}(\mathrm{X} \mid \mathrm{C} 1)<$ $(\mathrm{P}\{\mathrm{X} \mid \mathrm{C} 2)$ maka kesimpulannya $\mathrm{C} 2$ tidak puas = "Tidak Puas". Maka akan di ambil dari nilai perbandingan paling besar dari $\mathrm{C} 1$ dan $\mathrm{C} 2$ untuk dijadikan hasil prediksi. 
4) Hasil output dari klasifikasi Naïve Bayes merupakan nilai akurasi dari pengujian yang dilakukan oleh algoritma Naïve Bayes dengan menggunakan Confusion matrix

5) untuk validasi menggunakan teknik 10-Fold Cross Validation.

\section{HASIL DAN PEMBAHASAN}

A. Pembahasan terhadap hasil Dataset

Dataset yang sudah dikumpulkan untuk prediksi kepuasan pelayanan akademik diambil dari kuesioner, kuesioner yang diambil dari mahasiswa prodi teknik informatika angkatan 20162019, data yang diperoleh sebanyak 117 data yang akan diolah menjadi data latih dan data uji. Untuk atribut data latih dan data uji dapat dilihat pada Tabel 1.

Tabel 1. Atribut Data Latih dan Data Uji

\begin{tabular}{|c|l|}
\hline No & \multicolumn{1}{|c|}{ Atribut } \\
\hline 1 & NIM \\
\hline 2 & Jenis Kelamin \\
\hline 3 & Kelas Mahasiswa \\
\hline 4 & Layanan Informasi Perkuliahan \\
\hline 5 & Layanan Keamanan Data Pribadi \\
\hline 6 & Layanan Informasi Nilai \\
\hline 7 & Layanan Pengajuan Judul Skripsi \\
\hline
\end{tabular}

\section{B. Preprossecing Data}

Dari data yang sudah didapatkan yaitu 117 dataset, maka selanjutnya dilakukan preprossecing data dengan cara mengcleaning data yang nantinya akan diolah dengan algoritma naive bayaes, hal ini dilakukan untuk menghindari data yang tidak lengkap ataupun mencegah terjadinya duplikasi data, yang kemudian ditransformasikan untuk mengelompokkan field-field atau atribut yang terpilih kedalam basis data baru. Untuk data cleaning dan data transformasi dapat diihat pada Tabel 2

Tabel 2. Data Cleaning dan Data Transformasi

\begin{tabular}{|c|c|c|l|c|c|c|c|c|}
\hline id & nim & jenis_k & \multicolumn{1}{|c|}{ kate } & l1 & $\mathbf{l 2}$ & $\mathbf{l 3}$ & $\mathbf{l 4}$ & label \\
\hline 1 & 42416002 & P & $\begin{array}{l}\text { Mahasiswa } \\
\text { Skripsi }\end{array}$ & Ya & Ya & Ya & Tidak & Puas \\
\hline 2 & 42416003 & L & $\begin{array}{l}\text { Mahasiswa } \\
\text { Skripsi }\end{array}$ & Ya & Ya & Tidak & Ya & Puas \\
\hline 3 & 42416004 & P & $\begin{array}{l}\text { Mahasiswa } \\
\text { Skripsi }\end{array}$ & Ya & Ya & Ya & Ya & $\begin{array}{c}\text { Tidak } \\
\text { Puas }\end{array}$ \\
\hline 4 & 42416005 & P & $\begin{array}{l}\text { Mahasiswa } \\
\text { Skripsi }\end{array}$ & Ya & Ya & Tidak & Tidak & $\begin{array}{l}\text { Tidak } \\
\text { Puas }\end{array}$ \\
\hline 5 & 42416007 & L & $\begin{array}{l}\text { Mahasiswa } \\
\text { Skripsi }\end{array}$ & Ya & Tidak & Ya & Ya & Puas \\
\hline 6 & 42416009 & L & Masiswa Belajar & Ya & Tidak & Ya & Ya & Puas \\
\hline 7 & 42416010 & L & $\begin{array}{l}\text { Mahasiswa } \\
\text { Skripsi }\end{array}$ & Ya & Ya & Ya & Ya & Puas \\
\hline
\end{tabular}




\begin{tabular}{|c|c|c|l|c|c|c|c|c|}
8 & 42416011 & L & Masiswa Belajar & Ya & Ya & Ya & Ya & $\begin{array}{c}\text { Tidak } \\
\text { Puas }\end{array}$ \\
\hline 9 & 42416013 & L & $\begin{array}{l}\text { Mahasiswa } \\
\text { Skripsi }\end{array}$ & Ya & Tidak & Ya & Tidak & $\begin{array}{c}\text { Tidak } \\
\text { Puas }\end{array}$ \\
\hline 10 & 42416015 & L & Masiswa Belajar & Ya & Ya & Ya & Ya & Puas \\
\hline 11 & 42416016 & L & $\begin{array}{l}\text { Mahasiswa } \\
\text { Skripsi }\end{array}$ & Tidak & Tidak & Tidak & Tidak & $\begin{array}{c}\text { Tidak } \\
\text { Puas }\end{array}$ \\
\hline 12 & 42416018 & L & $\begin{array}{c}\text { Mahasiswa } \\
\text { Skripsi }\end{array}$ & Ya & Ya & Tidak & Tidak & Puas \\
\hline
\end{tabular}

\section{Klasifikasi}

Untuk klasifikasi data yang digunakan adalah naïve bayes classifier, proses ini digunakan dari awal perhitungan ketika proses training data sampai dengan prediksi data yang baru (data testing). Dengan ilustrasi pengklasifikasian sebagai berikut:

Mengitung prior probability

$\frac{C 1(\text { class label }=\text { "puas" })}{\text { total data }}=\frac{48}{100}=0,48$

$\frac{C 2(\text { class label }=\text { "tidak puas" })}{\text { total data }}=\frac{52}{100}=0,52$

$\frac{P(\text { l4 "ya"I class label "puas" })}{\text { puas }}=\frac{40}{48}=0,77$

$\frac{P(\text { l4 "ya"l class label "tidak puas" })}{\text { tidak puas }}=\frac{47}{52}=0,98$

$\frac{P(l 4 \text { "tidak"l } \text { class label "puas" })}{\text { tidak puas }}=\frac{40}{52}=0,77$

$\frac{P(14 \text { "tidak"l class label "tidak puas" })}{\text { tidak puas }}=\frac{12}{52}=0,23$

$\frac{P(\text { l3 "ya"l class label "puas" })}{\text { puas }}=\frac{39}{48}=0,81$

$\frac{P(\text { l3 "ya"l class label "tidak puas" })}{\text { puas }}=\frac{9}{48}=0,19$

$\frac{P(\text { l3 "tidak"l class label "puas" })}{\text { tidak puas }}=\frac{}{52}=0,77$

$\frac{P(\text { l3 "tidak"l class label "tidak puas" })}{\text { tidak puas }}=\frac{12}{52}=0,23$

$\mathrm{P}(\mathrm{X}$ Puas $)=\mathrm{P}($ Puas $) * \mathrm{P}\left(\frac{\text { Ya atau tidak }}{\text { Puas }}\right) *\left(\frac{\text { Ya atau tidak }}{\text { Puas }}\right) *\left(\frac{\text { Ya atau tidak }}{\text { Puas }}\right) *\left(\frac{\text { Ya atau tidak }}{\text { Puas }}\right) *$ $\left(\frac{\text { mhs skripsi atau mhsbelajar }}{\text { puas }}\right) *\left(\frac{\mathrm{L} \text { atau } \mathrm{P}}{\text { Puas }}\right)$

$P(\mathrm{Xl}$ Tidak Puas $)) \mathrm{P}\left(\right.$ Tic $^{1-1}$ Puas $) * \mathrm{P}\left(\frac{\text { Ya atau tidak }}{\text { Tidak Puas }}\right) *\left(\frac{\text { Ya atau tidak }}{\text { Tidak Puas }}\right) *\left(\frac{\text { Ya atau tidak }}{\text { Puas }}\right)$

$*\left(\frac{\text { Ya a }}{\text { Tic }}=\frac{£ \text { tidak }}{\text { : Puas }}\right) *\left(\frac{\text { mhs skripsi atau mhsbela jar }}{\text { Tidak puas }}\right) *\left(\frac{\mathrm{L} \text { atau } \mathrm{P}}{\text { Tidak Puas }}\right)$ 
Jatisi

ISSN 2407-4322

Vol. 7, No. 3, Desember 2020, Hal. 601-609 E- ISSN 2503-2933

Tabel 3. Data Training

\begin{tabular}{|c|c|c|c|c|c|c|c|}
\hline id & jenis_k & kate & 11 & 12 & 13 & 14 & label \\
\hline 1 & $\mathrm{P}$ & $\begin{array}{l}\text { Mahasiswa } \\
\text { Skripsi }\end{array}$ & Ya & Ya & Ya & Tidak & Puas \\
\hline 2 & $\mathrm{~L}$ & $\begin{array}{l}\text { Mahasiswa } \\
\text { Skripsi }\end{array}$ & Ya & Ya & Tidak & Tidak & Tidak Puas \\
\hline 3 & $\mathrm{P}$ & $\begin{array}{l}\text { Mahasiswa } \\
\text { Skripsi }\end{array}$ & Ya & Ya & Ya & Ya & Tidak Puas \\
\hline 4 & $\mathrm{P}$ & $\begin{array}{l}\text { Mahasiswa } \\
\text { Skripsi }\end{array}$ & Ya & Ya & Ya & Tidak & Puas \\
\hline 5 & $\mathrm{~L}$ & $\begin{array}{l}\text { Mahasiswa } \\
\text { Skripsi }\end{array}$ & Ya & Ya & Tidak & Ya & Puas \\
\hline 6 & $\mathrm{~L}$ & Masiswa Belajar & $\mathrm{Ya}$ & $\mathrm{Ya}$ & $\mathrm{Ya}$ & $\mathrm{Ya}$ & Puas \\
\hline 7 & $\mathrm{~L}$ & $\begin{array}{l}\text { Mahasiswa } \\
\text { Skripsi }\end{array}$ & Ya & Ya & Tidak & Tidak & Tidak Puas \\
\hline 8 & $\mathrm{~L}$ & Masiswa Belajar & $\mathrm{Ya}$ & $\mathrm{Ya}$ & $\mathrm{Ya}$ & $\mathrm{Ya}$ & Puas \\
\hline 9 & $\mathrm{~L}$ & $\begin{array}{l}\text { Mahasiswa } \\
\text { Skripsi }\end{array}$ & Ya & Tidak & Ya & Tidak & Tidak Puas \\
\hline 10 & $\mathrm{~L}$ & Masiswa Belajar & $\mathrm{Ya}$ & $\mathrm{Ya}$ & $\mathrm{Ya}$ & $\mathrm{Ya}$ & Puas \\
\hline 11 & $\mathrm{~L}$ & $\begin{array}{l}\text { Mahasiswa } \\
\text { Skripsi }\end{array}$ & Tidak & Tidak & Tidak & Tidak & Tidak Puas \\
\hline 12 & $\mathrm{~L}$ & $\begin{array}{l}\text { Mahasiswa } \\
\text { Skripsi }\end{array}$ & Ya & Ya & Tidak & Ya & Puas \\
\hline
\end{tabular}

Tabel 4. Data Testing

\begin{tabular}{|c|c|c|c|c|c|c|c|}
\hline id & jenis_k & kate & $\mathbf{l 1}$ & $\mathbf{1 2}$ & $\mathbf{1 3}$ & $\mathbf{1 4}$ & label \\
\hline 1 & L & Masiswa Belajar & Tidak & Ya & Ya & Ya & \\
\hline 2 & L & Masiswa Belajar & Ya & Ya & Ya & Ya & \\
\hline 3 & L & Masiswa Belajar & Ya & Ya & Ya & Ya & \\
\hline 4 & L & Masiswa Belajar & Ya & Ya & Ya & Ya & \\
\hline 5 & L & Masiswa Belajar & Ya & Ya & Ya & Ya & \\
\hline 6 & L & Masiswa Belajar & Tidak & Ya & Tidak & Ya & \\
\hline 7 & P & Masiswa Belajar & Ya & Ya & Ya & Ya & \\
\hline 8 & L & Masiswa Belajar & Tidak & Ya & Ya & Ya & \\
\hline 9 & L & Masiswa Belajar & Ya & Tidak & Ya & Ya & \\
\hline 10 & L & Masiswa Belajar & Ya & Ya & Ya & Ya & \\
\hline 11 & L & Masiswa Belajar & Ya & Ya & Ya & Ya & \\
\hline
\end{tabular}

D. Hasil

Nilai Data Training Puas $=52$ Nilai Data Training Tidak Puas $=48$ Nilai Data Uji $=17$ $\mathrm{p} 1($ Ya Puas $)=41 \mathrm{p} 1($ Tidak Tidak Puas $)=11 \mathrm{p} 1($ Ya Tidak Puas $)=31 \mathrm{p} 1($ Tidak Puas $)=17$ $\mathrm{p} 2($ Ya Tidak Puas $)=45 \mathrm{p} 2($ Tidak Tidak Puas $)=7 \mathrm{p} 2($ Ya Puas $)=45 \mathrm{p} 2($ Tidak Puas $)=3$ $\mathrm{p} 3($ Tidak Tidak Puas $)=17 \mathrm{p} 3($ Ya Tidak Puas $)=35 \mathrm{p} 3$ (Tidak Puas $)=9 \mathrm{p} 3($ Ya Puas $)=39$ $\mathrm{p} 4($ Tidak Tidak Puas $)=12 \mathrm{p} 4($ Ya Tidak Puas $)=40 \mathrm{p} 4($ Tidak Puas $)=1 \mathrm{p} 4($ Ya Puas $)=47$ jenis_k $($ P Tidak Puas $)=14$ jenis_k $($ L Tidak Puas $)=38$ jenis_k $($ L Puas $)=32$ jenis_k $(P$ Puas $)$ 


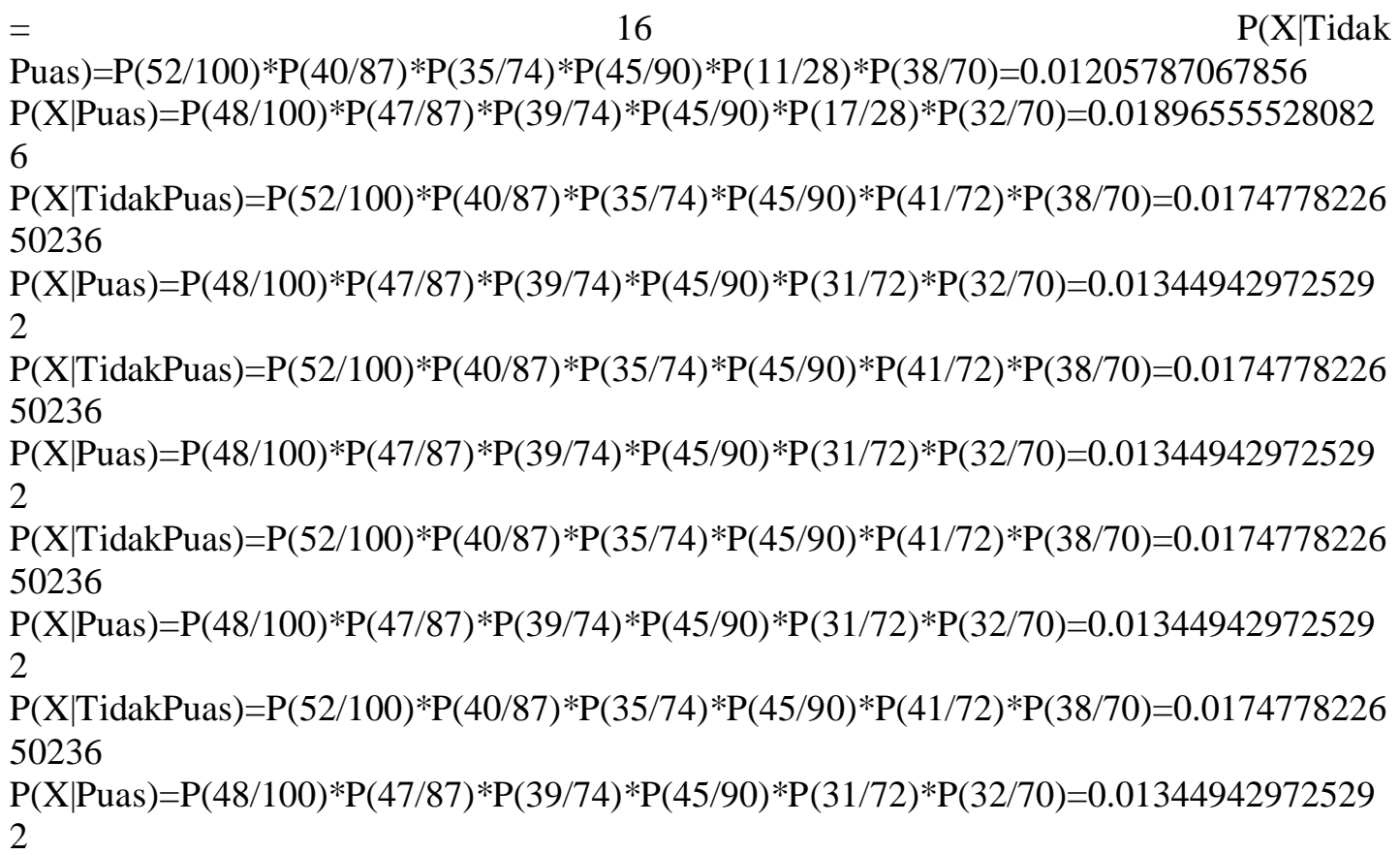

\section{KESIMPULAN}

Implementasi data mining dengan algoritma naïve bayes dapat dilakukan untuk memprediksi kepuasan layanan akademik di Universitas Peradaban dengan akurasi yang diperoleh adalah sebesar $52 \%$ untuk kepuasan penggunaan layanan akademik dengan menggunakan data training 100 data dan 17 data uji.

\section{SARAN}

Melakukan perancangan user interface untuk implementasi algoritma naïve bayes serta dapat menggunakan algoritma lain selain algoritma naïve bayes untuk mendapatkan hasil akurasi terbaik.

\section{DAFTAR PUSTAKA}

[1] J. Selatan, 2017, “Indeks Kepuasan Mahasiswa Terhadap Pelayanan," Vol. 7, No. 3, pp. 272-285.

[2] D. A. Kurniawan and D. Kriestanto, 2016, "Penerapan Nä̈ve Bayes Untuk Prediksi Kelayakan Kredit,” Vol. 1, No. 1, pp. 19-23.

[3] P. Studi and T. Informatika, 2018, "Evaluasi Kinerja Akademik Mahasiswa Menggunakan Algoritma Naive Bayes Classifier ( Studi Kasus STMIK Dipanegara )," Vol. VII, No. 1, pp. 193-202. 
[4] A. I. Jamhur, 2016, “Penerapan Data Mining Untuk Menganalisa Jumlah,” Vol. 23, No. 2, pp. 12-20.

[5] D. Teknik, I. Universitas, N. Bayes, N. Bayes, and N. Bayes, "Penerapan Algoritma Naive Bayes Untuk Mengklasifikasi Data Nasabah."

[6] T. H. Apandi, C. A. Sugianto, and C. R. Service, 2019, "Algoritma Naive Bayes untuk Prediksi Kepuasan Pelayanan Perekaman e-KTP Naive Bayes Algorithm for Satisfaction Prediction of e-ID," Vol. 7, No. November, pp. 125-128.

[7] A. V. Pakpahan and H. Irawan, 2017, "Penerapan Algoritma Naive Bayes Untuk Menentukan Nasabah Potensial pada AJB BUMIPUTERA 1912," Vol. 10, No. 2.

[8] S. Kasus and S. Pringsewu, "Analisis Kepuasan Mahasiswa Terhadap Pelayanan Akademik Menggunakan Metode Algoritma C4 . 5, 2016," Vol. 02, No. 01, pp. 1-11.

[9] N. Nasution et al., 2015, "Evaluasi Kinerja Akademik Mahasiswa Menggunakan Algoritma Nä̈ve Bayes (Studi Kasus: Fasilkom Unilak)," pp. 1-11.

[10] A. E. Wicaksono, J. T. Informatika, U. Gunadarma, and P. Data, 2016, "Implementasi Data Mining Dalam Pengelompokan Data Peserta Didik di Sekolah Untuk Memprediksi Calon Penerima Beasiswa Dengan Menggunakan Algoritma K- Means (Studi Kasus SMAN 16 Bekasi)," Vol. 21, No. 3.

[11] P. Studi, S. Informasi, and U. K. Indonesia, 2016, "Penerapan Nä̈ve Bayes Classifier Untuk Pemilihan Konsentrasi Mata Kuliah,"

[12] A. N. Putri, 2017, "Penerapan Naive Bayesian Untuk Perankingan Kegiatan di Fakultas Tik Universitas Semarang,” Vol. 8, No. 2, pp. 603-610. 